\title{
Effect of a paclitaxel-eluting metallic stent on rabbit esophagus
}

\author{
YIN ZHANG $^{1,2^{*}}$, YING GAO $^{3 *},{\text { JIANPING } \mathrm{CHEN}^{1}, \text { LIMEI MA }^{2}, \text { LI LIU }^{2}, \text { XIANG WANG }}^{2}$ and ZHINING FAN $^{2,3}$ \\ ${ }^{1}$ Department of Gastroenterology, The Third Affiliated Hospital of Soochow University, Changzhou, Jiangsu 213003; \\ ${ }^{2}$ Department of Digestive Endoscopy, The First Affiliated Hospital of Nanjing Medical University, Nanjing, Jiangsu 210011; \\ ${ }^{3}$ Department of Gastroenterology, The Second Affiliated Hospital of Nanjing \\ Medical University, Nanjing, Jiangsu 210029, P.R. China
}

Received January 14, 2015; Accepted February 18, 2016

DOI: $10.3892 /$ etm.2016.3708

\begin{abstract}
The use of self-expanding metallic stents (SEMS) is the current treatment of choice for malignant gastrointestinal obstructions. A paclitaxel-eluting metallic SEMS (PEMS) may have an antitumor effect on esophageal tissue. PEMS with $10 \%$ paclitaxel or conventional SEMS were inserted into the lower esophagus of rabbits. Following the insertion of the stents for 1,2, 4 and 6 weeks, the rabbits were sacrificed and the status of the stent insertion was examined, as well as any macroscopic or microscopic mucosal changes in the esophageal tissue. All the rabbits survived until death without any complications. No migration following stent insertion occurred. The number of cases with proximal obstruction increased in a time-dependent manner, and no significant difference was observed between the two groups. Gross histological examination showed similar tissue reaction to the stents at 1,2 and 4 weeks, and inflammatory cell infiltrating was higher in the SEMS group at 1 and 2 weeks. However, inflammatory cell infiltration was markedly higher in the PEMS group at 4 and 6 weeks. Food-intake and weight were similar in the two groups. The results of the present study demonstrated that PEMS may serve as a safe alternative treatment strategy for esophageal obstruction. Furthermore, PEMS may inhibit the tumor growth of the esophageal wall through inflammatory infiltration and targeted drug delivery. A tumor model will be required in the future for evaluating the prognosis of patients with advanced esophageal carcinoma.
\end{abstract}

Correspondence to: Professor Jianping Chen, Department of Gastroenterology, The Third Affiliated Hospital of Soochow University, 185 Juqian Street, Changzhou, Jiangsu 213003, P.R. China E-mail: chenjianping2016@outlook.com

*Contributed equally

Key words: paclitaxel-eluting metal stent, self-expanding metallic stents, rabbit, esophageal carcinoma, endoscopy

\section{Introduction}

Esophageal cancer is one of the most common malignances worldwide, and is especially prevalent in China and Japan $(1,2)$. Patients with esophageal cancer have a poor prognosis due to dysphagia (3). Surgery is the only form of treatment that can provide a cure for esophageal cancer, although it is suitable for less than a third of patients due to late diagnosis, advanced progress and tumor metastasis (4). In recent decades, metallic stent insertion into the esophagus has been widely used in the treatment of esophageal cancer as it is less invasive, prolongs survival and improves life quality (5). However, conventional stents can only facilitate drainage but have no antitumor effect. Furthermore, the side-effects following stent insertion are non-negligible, and include tumor overgrowth, tumor ingrowth and granulation tissue hyperplasia at either end of the stent (6).

In recent years, several studies have been carried out on the use of drug-eluting metallic stents for digestive system carcinoma, including a 5-Fu-eluting stent for esophagal cancer and a paclitaxel-eluting stent for biliary duct and esophagal cancers $(7,8)$. The majority of the results demonstrated that self-expanding metallic stents (SEMS) combined with an antitumor drug allowed the targeting of the drug to the wall tissue and the maintenance of a controlled treatment dose over long periods of time $(7,8)$.

Paclitaxel is as a novel anti-neoplastic agent currently used to treat several types of cancer (9). Paclitaxel has been demonstrated to be effective at inhibiting the proliferation of human gallbladder epithelial cells, fibroblasts, pancreatic adenocarcinoma cells and esophageal cells (10). In addition, Jeon et al (10) reported that paclitaxel-eluting metallic SEMS (PEMS) inhibited tissue hyperplasia in the esophagus, and may manage refractory benign esophageal stricture (10). Paclitaxel exerts its pharmacological effects by binding to $\beta$-tubulin and by stabilizing the polymerized microtubules (11). Therefore, paclitaxel can be coated on the SEMS in order to provide sustained release (12).

In our previous study, an esophageal squamous carcinoma was created in rabbits using an endoscopic technique (13). In addition, a previous study demonstrated that the in vitro sustained release of PEMS with $10 \%$ paclitaxel lasted for 
$>40$ days, which was sufficient for observing the effect of the drug on the rabbit esophagus (14). The aim of the current study is to evaluate the safety of PEMS in the rabbit esophagus and to investigate the effect of PEMS on esophageal tissue.

\section{Materials and methods}

Preparation of PEMSs. The SEMS used in the present study (Niti-S polyurethane-covered stent; Garson-Flextent, Jiangsu, China) were $16 \mathrm{~mm}$ long, $10 \mathrm{~mm}$ wide in the middle and $12 \mathrm{~mm}$ wide at the proximal end of the stent when fully expanded and mounted on a $7 \mathrm{~F}$ stent introducer set custom made by Garson-Flextent. Due to the fact that the average diameter of the rabbit esophagus is $\sim 5 \mathrm{~mm}$, a stent with a $12 \mathrm{~mm}$ diameter flare was considered sufficient to prevent stent migration. The PEMS were loaded with $10 \%$ (wt/vol) paclitaxel $\left(\right.$ Taxol $^{\circledR}$; Jiangsu Hongdoushan Biological Technology Co., Ltd., Jiangsu, China) by the State Key Laboratory of Pharmaceutical Biotechnology, School of Life Sciences, Nanjing University (Nanjing, China). Following the determination of the eluting stent indices including release rates and effect on the mucosa, PEMSs with $10 \%$ paclitaxel was shown to be the most suitable choice.

\section{Animal study}

Stent placement. All experimental procedures were performed in accordance with the National Institutes of Health guidelines for humane handling of animals and were approved by the Committee on Animal Research at our institution (15). Male New Zealand white rabbits ( $n=48$; Jiangsu Academy of Agricultural Science, Jiangsu, China), weighing 1.5-2.0 kg and housed in an environment with a 12 -h dark:light cycle at $25^{\circ} \mathrm{C}$ with free access to food and water, were randomly assigned to a PEMS group or a SEMS group (6 rabbits in each group per time-point).

Due to the fact that the rabbit malignant stricture model was created recently in our previous study, a normal rabbit model $(13,16)$ was used in the present study. A total of 48 rabbits with malignant esophageal occlusion were fasted for $24 \mathrm{~h}$ prior to stent implantation. Each rabbit was anesthetized by intraperitoneal injection with $95 \%$ pentobarbital sodium (35 mg/kg; Sigma-Aldrich, St. Louis, MO, USA). Each rabbit was then placed in the left lateral position. A SEMS or PEMS was introduced into the esophagus using the $7 \mathrm{~F}$ stent introducer set. Prior to the placement of the introducer at the correct site, 1-2 ml contrast medium (Iohexol; GE Healthcare Life Sciences, Chalfont, UK) was injected into the esophagus in order to confirm the accurate position of the stent. The stent was then deployed in the lower esophagus. All endoscopic procedures were performed by two well-experienced endoscopists.

Follow-up and postmortem examination. Following endoscopic stent placement, the animals were fasted for a further $24 \mathrm{~h}$ prior to reintroduction of their usual diet. During the follow-up, food-intake and weight were monitored. On the 1st, 2nd, 4th and 6th week following stent insertion, 6 rabbits in each group were sacrificed by intravascular air embolism. The esophagus was excised and examined grossly. Images were captured in order to examine the status of the proximal esophageal obstruction due to inflammation hyperplasia. Each stent was gently removed from the esophagus, and the esophagus was then incised longitudinally. Esophageal wall hyperemia and proximal obstruction was evaluated. Hyperemia was graded as follows: 0, hyperemia absent; 1 , hyperemia present. Proximal obstruction was graded as follows: 0 , normal; 1 , stricture; 2 , obstruction. Following gross tissue evaluation, the lesion tissue samples were fixed in $10 \%$ formalin or stored at $-80^{\circ} \mathrm{C}$. Tissue samples [paclitaxel-covered segment and proximal uncovered stented segment (the part of the stent without the membrane)] were stained with hematoxylin and eosin (Wuhan Boster Biological Technology, Ltd., Wuhan, China) and examined by an experienced gastrointestinal pathologist using a CX23 Microscope (Olympus Corporation, Tokyo, Japan). Weight, food-intake, stent migration hyperemia and proximal obstruction were also recorded.

A single pathologist evaluated the status of the proximal uncovered stented segment, the thickness of the epithelial layer and submucosal inflammatory cell infiltration. Thickening of the epithelial layer was defined as the distance between the tissue protruding into the lumen and the lower portion of the submucosa. The thickened epithelial layer was defined as follows: 0 , normal; 1 , mild; 2 , severe. The degree of submucosal inflammatory cell infiltration was graded as follows: 0, none; 1 , mild (scattered inflammatory cells); 2, moderate (inflammatory cell infiltration in $\sim$ half of a microscopic field); 3 , severe (inflammatory cells infiltration in the majority or all of the microscopic field) (17).

Two endoscopists performed the stent insertion and recorded which stent (SEMS or PEMS) was inserted. Subsequently, a pathologist blinded to the type of stent inserted examined the tissue samples both grossly and microscopically.

Statistical analysis. The data are expressed as means \pm standard error of the mean. Continuous variables were compared by unpaired Student t-test including food-intake following stent implantation, weight at the time of sacrifice, proximal esophageal obstruction, tissue hyperemia, thickness of each epithelial layer, and submucosal inflammatory cell infiltration. One-way analysis of variance and Fisher's exact test were used to analyze hyperemia, degree of proximal obstruction, thickness of the epithelial layer and degree of inflammatory cell infiltration in the SEMS and PEMS groups. SPSS version 13.0 software (SPSS Inc., Chicago, IL, USA) was used for all statistical analyses. $\mathrm{P}<0.05$ was considered to indicate a statistically significant result.

\section{Results}

Stent placement and follow-up. The 48 rabbits were anesthetized and the stents were placed into their esophagus. All rabbits survived the procedure. There were no procedure-associated complications such as abdominal infection or pneumonia. All the stents were in situ and no migration occurred following stent insertion in any of the rabbits. Following insertion of the stents for 1,2, 4 and 6 weeks, 6 rabbits were sacrificed in each group and gross and microscopic examination of the esophageal tissue was performed. The weight and food-intake was similar in the two groups. 
Table I. Characteristics of the 12 rabbits sacrificed 1 week following stent insertion.

\begin{tabular}{|c|c|c|c|c|c|c|c|}
\hline \multirow[b]{3}{*}{ Rabbit } & \multirow[b]{3}{*}{$\begin{array}{l}\text { Weight } \\
(\mathrm{kg})\end{array}$} & \multirow[b]{3}{*}{$\begin{array}{c}\text { Food-intake } \\
\text { (g) }\end{array}$} & \multirow{2}{*}{\multicolumn{3}{|c|}{ Gross findings }} & \multicolumn{2}{|c|}{ Microscopic findings } \\
\hline & & & & & & \multirow{2}{*}{$\begin{array}{c}\text { Thickness of } \\
\text { epithelial } \\
\text { layer }\end{array}$} & \multirow{2}{*}{$\begin{array}{c}\text { Degree of } \\
\text { inflammatory cell } \\
\text { infiltration }\end{array}$} \\
\hline & & & Migration & Hyperemia & $\begin{array}{c}\text { Proximal } \\
\text { obstruction }\end{array}$ & & \\
\hline SEMS 1 & 1.98 & 150 & 0 & 1 & 0 & 1 & 3 \\
\hline SEMS 2 & 2.03 & 180 & 0 & 0 & 0 & 1 & 2 \\
\hline SEMS 3 & 1.88 & 120 & 0 & 1 & 0 & 1 & 3 \\
\hline SEMS 4 & 2.10 & 130 & 0 & 1 & 0 & 0 & 3 \\
\hline SEMS 5 & 1.95 & 180 & 0 & 1 & 0 & 0 & 2 \\
\hline SEMS 6 & 2.20 & 200 & 0 & 0 & 0 & 0 & 3 \\
\hline PEMS 1 & 1.90 & 130 & 0 & 1 & 0 & 1 & 2 \\
\hline PEMS 2 & 1.79 & 180 & 0 & 1 & 0 & 1 & 1 \\
\hline PEMS 3 & 2.01 & 200 & 0 & 1 & 0 & 0 & 1 \\
\hline PEMS 4 & 1.85 & 150 & 0 & 1 & 0 & 1 & 1 \\
\hline PEMS 5 & 1.90 & 110 & 0 & 0 & 0 & 1 & 2 \\
\hline PEMS 6 & 1.86 & 200 & 0 & 1 & 0 & 1 & 1 \\
\hline P-value & 0.03 & 0.94 & 1 & 1 & 1 & 0.26 & $<0.01$ \\
\hline
\end{tabular}

PEMS vs. SEMS. Migration scores: 0, migration absent; 1, migration present. Hyperemia scores: 0, hyperemia absent; 1 , hyperemia present. Proximal obstruction scores: 0 , normal; 1 , stricture. Thickness of the epithelial layer scores: 0 , normal; 1 , mild. Degree of inflammatory cell infiltration: 1, mild; 2, moderate; 3, severe. SEMS, self-expanding metallic stents; PEMS, Paclitaxel-eluting metallic SEMS.

Table II. Characteristics of the 12 rabbits sacrificed 2 weeks following stent insertion.

\begin{tabular}{|c|c|c|c|c|c|c|c|}
\hline \multirow[b]{3}{*}{ Rabbit } & \multirow[b]{3}{*}{$\begin{array}{l}\text { Weight } \\
(\mathrm{kg})\end{array}$} & \multirow[b]{3}{*}{$\begin{array}{l}\text { Food-intake } \\
\qquad(\mathrm{g})\end{array}$} & \multirow{2}{*}{\multicolumn{3}{|c|}{ Gross findings }} & \multicolumn{2}{|c|}{ Microscopic findings } \\
\hline & & & & & & \multirow{2}{*}{$\begin{array}{l}\text { Thickness of } \\
\text { epithelial } \\
\text { layer }\end{array}$} & \multirow{2}{*}{$\begin{array}{c}\text { Degree of } \\
\text { inflammatory cell } \\
\text { infiltration }\end{array}$} \\
\hline & & & Migration & Hyperemia & $\begin{array}{c}\text { Proximal } \\
\text { obstruction }\end{array}$ & & \\
\hline SEMS 1 & 2.40 & 150 & 0 & 1 & 1 & 1 & 2 \\
\hline SEMS 2 & 2.29 & 170 & 0 & 0 & 0 & 0 & 2 \\
\hline SEMS 3 & 2.60 & 200 & 0 & 0 & 1 & 1 & 3 \\
\hline SEMS 4 & 2.55 & 180 & 0 & 1 & 1 & 0 & 3 \\
\hline SEMS 5 & 2.04 & 200 & 0 & 0 & 0 & 0 & 2 \\
\hline SEMS 6 & 2.59 & 200 & 0 & 0 & 0 & 1 & 2 \\
\hline PEMS 1 & 2.44 & 160 & 0 & 1 & 0 & 1 & 2 \\
\hline PEMS 2 & 2.38 & 180 & 0 & 1 & 1 & 1 & 1 \\
\hline PEMS 3 & 2.09 & 160 & 0 & 1 & 0 & 1 & 2 \\
\hline PEMS 4 & 2.32 & 180 & 0 & 0 & 1 & 0 & 1 \\
\hline PEMS 5 & 2.20 & 180 & 0 & 1 & 1 & 0 & 2 \\
\hline PEMS 6 & 2.06 & 200 & 0 & 1 & 1 & 0 & 2 \\
\hline P-value & 0.17 & 0.54 & 1 & 0.09 & 1 & 1 & 0.04 \\
\hline
\end{tabular}

PEMS vs. SEMS. Migration scores: 0, migration absent; 1, migration present. Hyperemia scores: 0, hyperemia absent; 1, hyperemia present. Proximal obstruction scores: 0 , normal; 1 , stricture. Thickness of the epithelial layer scores: 0 , normal; 1 , mild. Degree of inflammatory cell infiltration: 1, mild; 2, moderate; 3 , severe. SEMS, self-expanding metallic stents; PEMS, Paclitaxel-eluting metallic SEMS.

Gross and microscopic findings. The middle and lower part of the esophagus was excised from the body. Gross inspection of the excised tissue specimens revealed no perforation or bleeding in any of the rabbits. No adhesion was found between the esophagus and surrounding organs. The esophagus was then incised longitudinally. At 1 week following stent insertion, 
Table III. Characteristics of the 12 rabbits sacrificed 4 weeks following stent insertion.

\begin{tabular}{|c|c|c|c|c|c|c|c|}
\hline \multirow[b]{2}{*}{ Rabbit } & \multirow[b]{2}{*}{$\begin{array}{l}\text { Weight } \\
(\mathrm{kg})\end{array}$} & \multirow[b]{2}{*}{$\begin{array}{c}\text { Food-intake } \\
\text { (g) }\end{array}$} & \multicolumn{3}{|c|}{ Gross findings } & \multicolumn{2}{|c|}{ Microscopic findings } \\
\hline & & & Migration & Hyperemia & $\begin{array}{c}\text { Proximal } \\
\text { obstruction }\end{array}$ & $\begin{array}{c}\text { Thickness of } \\
\text { epithelial } \\
\text { layer }\end{array}$ & $\begin{array}{c}\text { Degree of } \\
\text { inflammatory } \\
\text { cell infiltration }\end{array}$ \\
\hline SEMS 1 & 2.57 & 200 & 0 & 0 & 1 & 2 & 1 \\
\hline SEMS 2 & 2.39 & 190 & 0 & 1 & 1 & 2 & 2 \\
\hline SEMS 3 & 2.80 & 200 & 0 & 0 & 1 & 1 & 1 \\
\hline SEMS 4 & 2.75 & 180 & 0 & 0 & 0 & 2 & 2 \\
\hline SEMS 5 & 2.34 & 180 & 0 & 0 & 0 & 2 & 1 \\
\hline SEMS 6 & 2.70 & 200 & 0 & 0 & 1 & 1 & 2 \\
\hline PEMS 1 & 2.87 & 200 & 0 & 1 & 0 & 1 & 3 \\
\hline PEMS 2 & 3.02 & 180 & 0 & 0 & 0 & 1 & 2 \\
\hline PEMS 3 & 2.31 & 170 & 0 & 1 & 0 & 0 & 3 \\
\hline PEMS 4 & 2.29 & 150 & 0 & 1 & 1 & 0 & 3 \\
\hline PEMS 5 & 2.40 & 180 & 0 & 0 & 1 & 2 & 2 \\
\hline PEMS 6 & 2.23 & 200 & 0 & 1 & 1 & 0 & 3 \\
\hline P-value & 0.66 & 0.21 & 1 & 0.09 & 1 & 0.03 & $<0.01$ \\
\hline
\end{tabular}

PEMS vs. SEMS. Migration scores: 0, migration absent; 1, migration present. Hyperemia scores: 0, hyperemia absent; 1, hyperemia present. Proximal obstruction scores: 0 , normal; 1 , stricture. Thickness of the epithelial layer scores: 0 , normal; 1 , mild; 2 , severe. Degree of inflammatory cell infiltration: 1 , mild; 2, moderate; 3 , severe. SEMS, self-expanding metallic stent; PEMS, Paclitaxel-eluting metallic SEMS.

Table IV. Characteristics of the 12 rabbits sacrificed 6 weeks following stent insertion.

\begin{tabular}{|c|c|c|c|c|c|c|c|}
\hline \multirow[b]{3}{*}{ Rabbit } & \multirow[b]{3}{*}{$\begin{array}{c}\text { Weight } \\
(\mathrm{kg})\end{array}$} & \multirow[b]{3}{*}{$\begin{array}{l}\text { Food-intake } \\
\text { (g) }\end{array}$} & \multirow{2}{*}{\multicolumn{3}{|c|}{ Gross findings }} & \multicolumn{2}{|c|}{ Microscopic findings } \\
\hline & & & & & & \multirow{2}{*}{$\begin{array}{c}\text { Thickness of } \\
\text { epithelial } \\
\text { layer }(\mu \mathrm{m})\end{array}$} & \multirow{2}{*}{$\begin{array}{c}\text { Degree of } \\
\text { inflammatory } \\
\text { cell infiltration }\end{array}$} \\
\hline & & & Migration & Hyperemia & $\begin{array}{c}\text { Proximal } \\
\text { obstruction }\end{array}$ & & \\
\hline SEMS 1 & 2.49 & 180 & 0 & 0 & 1 & 2 & 1 \\
\hline SEMS 2 & 2.52 & 180 & 0 & 0 & 1 & 2 & 1 \\
\hline SEMS 3 & 2.83 & 170 & 0 & 0 & 1 & 2 & 0 \\
\hline SEMS 4 & 2.94 & 180 & 0 & 0 & 0 & 1 & 0 \\
\hline SEMS 5 & 2.78 & 180 & 0 & 0 & 1 & 2 & 1 \\
\hline SEMS 6 & 2.80 & 170 & 0 & 0 & 1 & 2 & 0 \\
\hline PEMS 1 & 2.74 & 200 & 0 & 0 & 1 & 1 & 2 \\
\hline PEMS 2 & 2.99 & 180 & 0 & 1 & 1 & 0 & 2 \\
\hline PEMS 3 & 2.75 & 190 & 0 & 1 & 1 & 2 & 3 \\
\hline PEMS 4 & 2.67 & 180 & 0 & 1 & 0 & 1 & 2 \\
\hline PEMS 5 & 2.93 & 170 & 0 & 0 & 1 & 1 & 1 \\
\hline PEMS 6 & 2.77 & 180 & 0 & 0 & 1 & 1 & 3 \\
\hline P-value & 0.38 & 0.19 & 1 & 0.04 & 1 & 0.02 & $<0.01$ \\
\hline
\end{tabular}

PEMS vs. SEMS. Migration scores: 0, migration absent; 1, migration present. Hyperemia scores: 0, hyperemia absent; 1 , hyperemia present. Proximal obstruction scores: 0 , normal; 1 , stricture. Thickness of the epithelial layer scores: 0 , normal; 1 , mild; 2 , severe. Degree of inflammatory cell infiltration: 0, none; 1, mild; 2, moderate; 3, severe. SEMS, self-expanding metallic stent; PEMS, Paclitaxel-eluting metallic SEMS.

4 and 5 rabbits with hyperemia were identified in the SEMS and PEMS group, respectively, although this difference was not significant $(\mathrm{P}>0.05)$, and no proximal obstruction at either end of the stent occurred in either groups. Epithelial thickness mildly increased in 3 and 5 rabbits in the SEMS and PEMS groups, respectively $(\mathrm{P}>0.05)$. However, inflammatory cell 
A

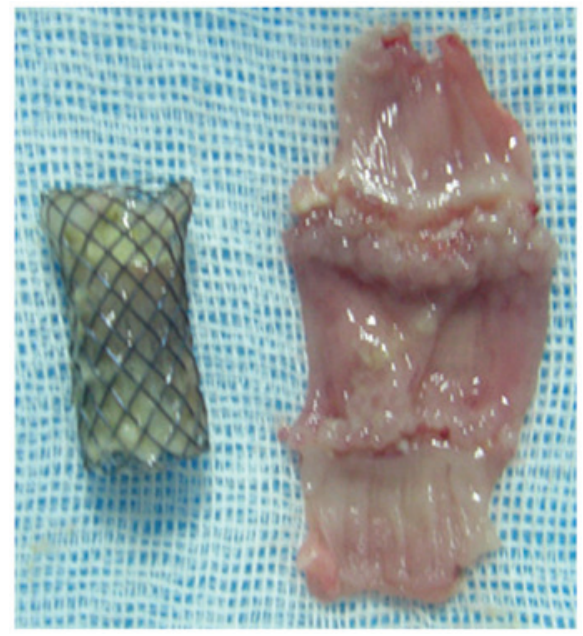

B

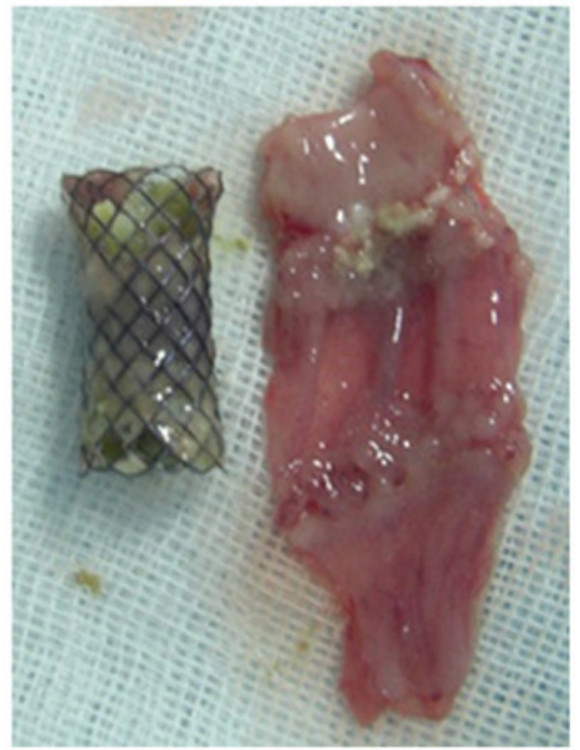

Figure 1. Gross examination of the excised esophagus. (A) The esophagus excised 4 weeks following stent insertion in the SEMS group and (B) PEMS group. SEMS, self-expanding metallic stents; PEMS, Paclitaxel-eluting metallic SEMS.

infiltration was determined to be significantly more severe in the SEMS group, as compared with the PEMS group $(\mathrm{P}<0.05)$. At 2 weeks following stent insertion, proximal stricture occurred (Table I) in 3 rabbits in the SEMS group and 4 rabbits in the PEMS group, although this difference was not statistically significant $(\mathrm{P}>0.05)$. Mucosal hyperemia occurred in 2 rabbits in the SEMS group, and 5 rabbits in the PEMS group $(\mathrm{P}>0.05)$. There was no statistically significant difference in the thickness of the epithelia in the two groups ( $\mathrm{P}>0.05)$. Inflammatory cell infiltration remained severe in the SEMS group and increased in the PEMS group $(\mathrm{P}<0.05)$. At 4 weeks following stent insertion, mucosal hyperemia occurred in 1 rabbit in the SEMS group and 4 rabbits in the PEMS group (Table II), although this difference was not statistically significant $(\mathrm{P}>0.05)$. Proximal stricture occurred in 4 rabbits in the SEMS group and 3 rabbits in the PEMS group $(\mathrm{P}>0.05)$. Epithelial thickness in the SEMS group was significantly higher, as compared with the PEMS group $(\mathrm{P}<0.05)$. Inflammatory cell infiltration started to decrease in the SEMS group, but increased in the PEMS group $(\mathrm{P}<0.05)$. At 6 weeks following stent insertion, stricture
A

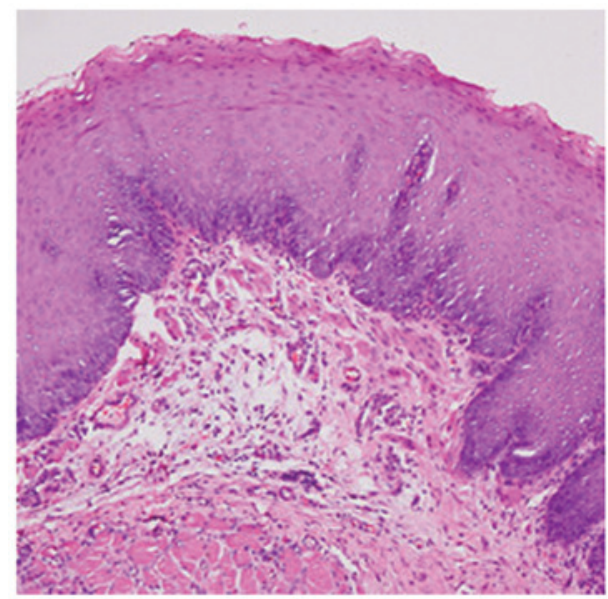

B

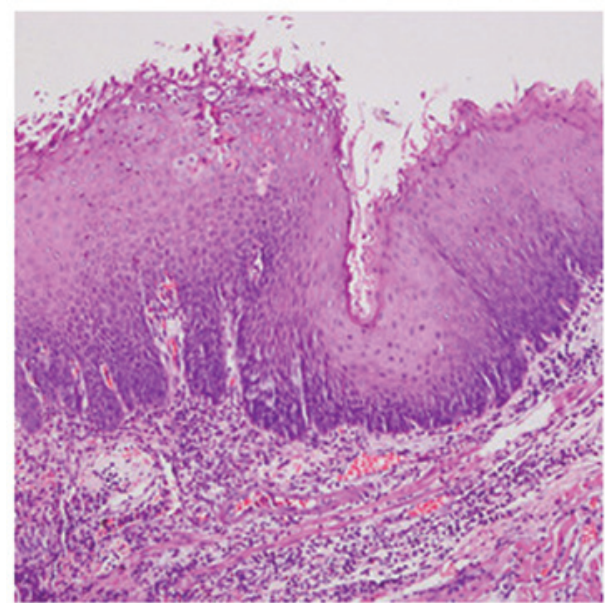

Figure 2. Microscopic examination of the esophagus stained with hematoxylin and eosin following stent insertion for 6 weeks (magnification, $x 400$ ). (A) In the SEMS group, the esophageal wall exhibits a thick epithelial layer with mild inflammatory cell infiltration. (B) In the PEMS group, the esophageal wall exhibits a thick epithelial layer with severe inflammatory cell infiltration. SEMS, self-expanding metallic stents; PEMS, Paclitaxel-eluting metallic SEMS.

occurred in the majority of the animals, but no obstruction was observed (Table III, Fig 1A and B); the amount of stricture was not significantly different between the SEMS and the PEMS group $(\mathrm{P}>0.05)$. No hyperemia was observed in the rabbits of the SEMS group, although 3 rabbits in PEMS group exhibited hyperemia $(\mathrm{P}<0.05)$. Epithelial thickness was significantly increased in the SEMS group, as compared with the PEMS group $(\mathrm{P}<0.05)$. Inflammatory cell infiltration was rarely observed in the SEMS group but remained severe in the PEMS group $(\mathrm{P}<0.05)$ (Table IV; Fig. 2A and B). The data was compared among different time points in the two groups. In the SEMS group, mucosal hyperemia and inflammatory cell infiltration decreased over time, and proximal stricture and thickness of the epithelia increased with the time (Fig. 3A-D). Conversely, in the PEMS group, mucosal hyperemia decreased over time, and proximal stricture, thickness of the epithelia and inflammatory cell infiltration increased over time (Fig 4A and B)

\section{Discussion}

Esophageal carcinoma is the 6th leading cause of cancer-associated mortality and the 8th most common cancer 
A

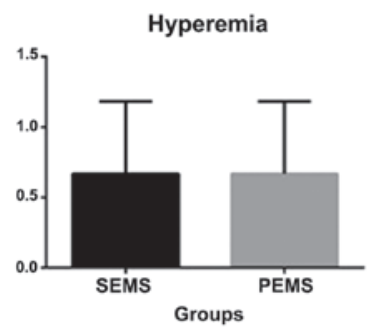

Thickness of epithelial layer

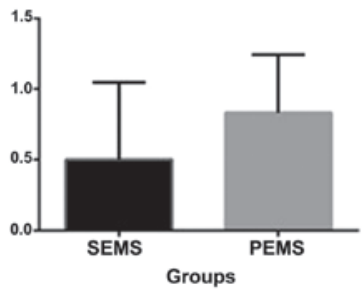

B

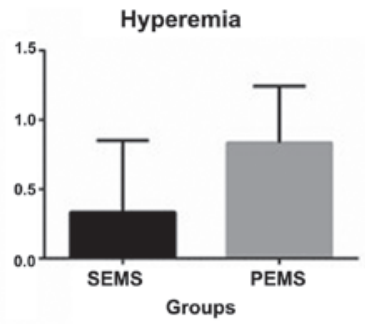

Thickness of epithelial layer

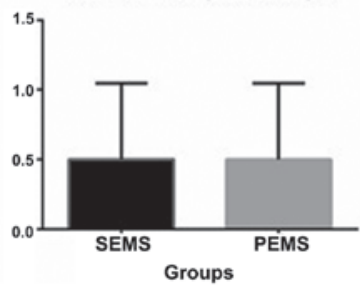

C

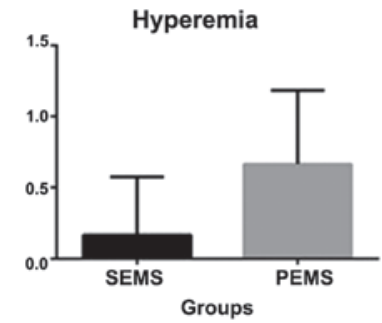

D Thickness of epithelial layer

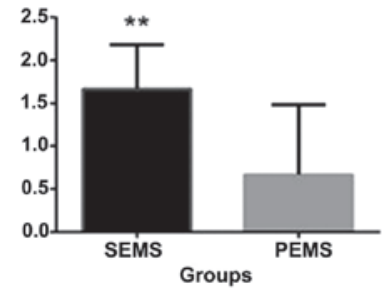

Proximal obstruction

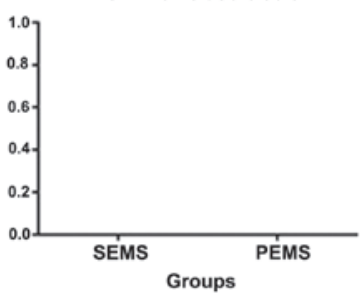

Inflammatory cell infiltration

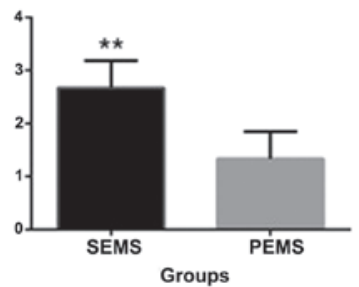

Proximal obstruction

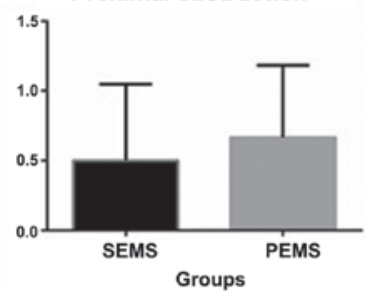

Inflammatory cell infiltration

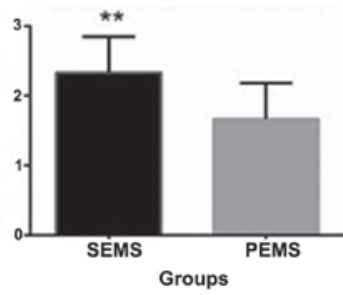

Proximal obstruction

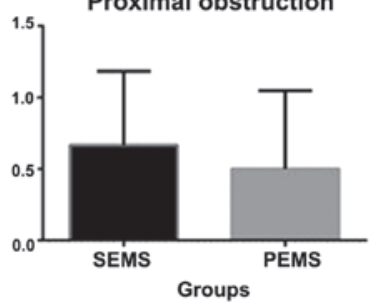

Inflammatory cell infiltration

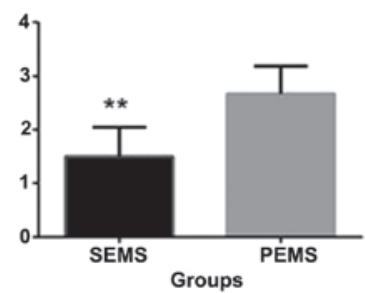

Figure 3. Hyperemia, degree of proximal obstruction, thickness of the epithelial layer and degree of inflammatory cell infiltration 1, 2, 4 and 6 weeks following stent insertion. (A) At 1 week, 4 and 5 rabbits exhibited hyperemia in the SEMS and PEMS group, respectively, and no proximal obstruction at either end of the stent occurred in either of the two groups. Epithelial thickness increased in 3 rabbits in the SEMS group and 5 rabbits in the PEMS group. Inflammatory cell infiltration was significantly higher in the SEMS group compared with the PEMS group. (B) At 2 weeks, mucosal hyperemia occurred in 2 rabbits in the SEMS group and 5 rabbits in the PEMS group. Proximal stricture occurred in 3 rabbits in the SEMS group and 4 rabbits in the PEMS group. The thickness of the epithelia was similar in both groups. Inflammatory cell infiltration was significantly higher in the SEMS group compared with the PEMS group. (C) At 4 weeks, mucosal hyperemia occurred in 1 rabbit and 4 rabbits in the SEMS and PEMS groups, respectively. Proximal stricture occurred in 4 rabbits in the SEMS group and 3 rabbits in the PEMS group. Epithelial thickness in the SEMS group was significantly higher compared with the PEMS group. Inflammatory cell infiltration was significantly lower in the SEMS group compared with the PEMS group. (D) At 6 weeks, stricture had occurred in the majority of the rabbits although no obstruction was observed. No hyperemia was observed in the SEMS group, and conversely 3 rabbits exhibited hyperemia in the PEMS group. Epithelial thickness was significantly higher in the SEMS group compared with the PEMS group. Inflammatory cell infiltration was significantly lower in the SEMS group compared with the PEMS group. ${ }^{* *} \mathrm{P}<0.05$, vs. the PEMS group. SEMS, self-expanding metallic stents; PEMS, Paclitaxel-eluting metallic SEMS. 
A

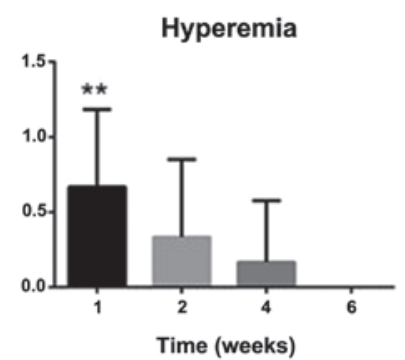

Thickness of epithelial layer

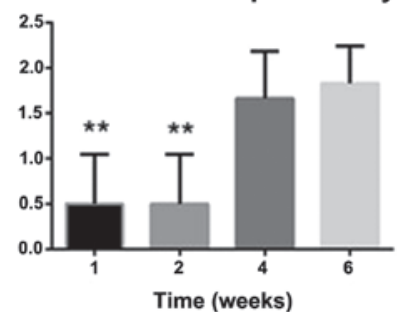

B

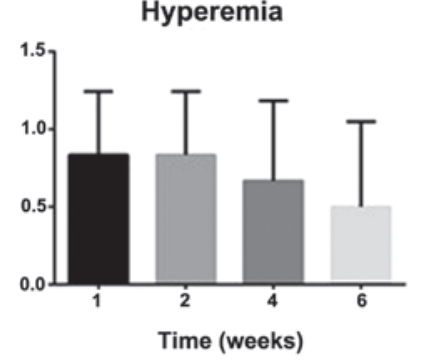

Thickness of epithelial layer

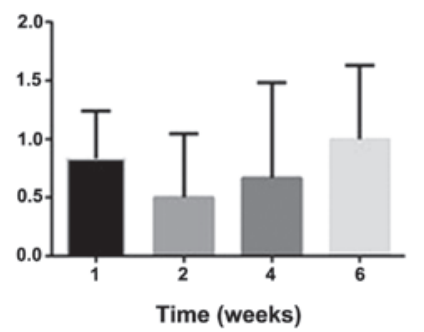

Proximal obstruction

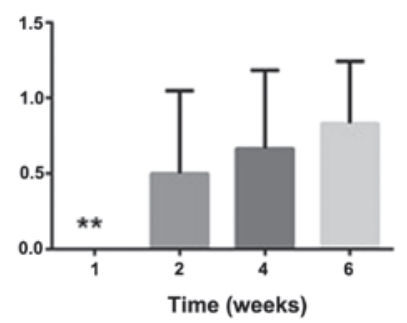

Inflammatory cell infiltration

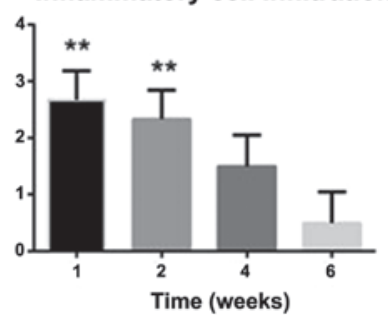

Proximal obstruction

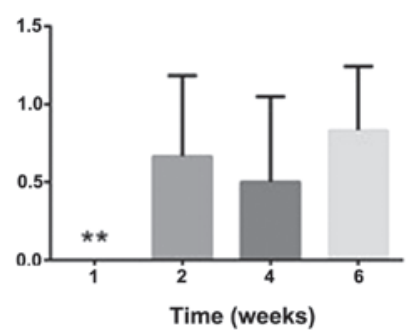

Inflammatory cell infiltration

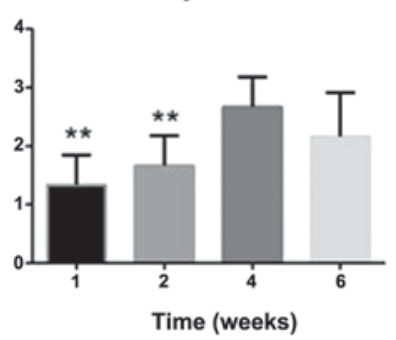

Figure 4. Hyperemia, degree of proximal obstruction, thickness of the epithelial layer and degree of inflammatory cell infiltration in the SEMS and PEMS groups. (A) In the SEMS group, mucosal hyperemia and inflammatory cell infiltration decreased over time. Conversely, proximal stricture and thickness of the epithelia increased with the time. (B) In the PEMS group, mucosal hyperemia decreased over time. Conversely, proximal stricture, thickness of the epithelia and inflammatory cell infiltration increased over time. ${ }^{* *} \mathrm{P}<0.05$, vs. the PEMS group. SEMS, self-expanding metallic stents; PEMS, Paclitaxel-eluting metallic SEMS.

worldwide $(18,19)$. Early resection of the cancer leads to a good prognosis (19). However, over half of patients with esophageal cancer are not eligible for surgical resection. Therefore, treatment of advanced esophageal carcinoma remains challenging (20). In recent decades, stent deployment in the esophagus has been widely used as a palliative therapy which reduces tumor ingrowth and facilitates drainage. The SEMS is easily inserted and provides adequate drainage in the esophagus. Furthermore, PEMS has the potential to inhibit tumor growth and some positive results have been published $(14,17)$.

In 2005, Lee et al (21) reported on the effect of PEMS on normal porcine bile ducts. The results demonstrated that treatment with PEMS resulted in epithelial denudation, mucin hypersecretion and epithelial metaplasia, which led to the hypothesis that PEMS may have anti-tumor effects on malignant biliary stricture in humans (21). In 2009, another study was performed on dogs which demonstrated that the epithelial layers were thicker in the PEMS group compared with the control group, and revealed that the local delivery of paclitaxel resulted in marked histological changes that may be associated with an antitumor effect (17). Furthermore, two small retrospective clinical studies on the use of PEMS for malignant biliary stricture reported controversial results, indicating that paclitaxel was unable to inhibit tumor growth and prolong survival-time in humans $(22,23)$. Conversely, Guo et al (24) revealed that Fu-eluting stents had prolonged release patterns and retained good integrity and stability following stent deployment. The 5 -Fu concentration in stent-adjacent tissue was markedly higher compared with that found in the serum or liver (19). 
We propose that paclitaxel may also have anti-tumor effects on squamous esophageal carcinoma. Large-sized animal models were widely used in previous studies for stent research $(14,17)$. However, these models were not usually conducted under disease conditions, and the animals were too large to be operated on and followed up. Furthermore, studies conducted on small animals, such as mice, used immunodeficient animals, and did not allow for stent deployment with an endoscope $(14,17,21,22)$. Therefore, in present study rabbits were selected as an animal model, as they are sufficiently large to allow for the oral insertion of an ultra-slim endoscope and stent introducer set $(25,26)$.

The results presented herein revealed the safety of PEMS and SEMS in the rabbit model. No major complications, including massive bleeding, perforation or fatal infection were observed. Conversely to previous studies $(27,28)$, no migration of the stents were observed in the present study. This may be due to the fact that stents with larger diameters were used, which enhanced the radical focus of the esophagus. The rabbit weight and food-intake was normal following stent deployment, which demonstrated that the stent did not affect the rabbits.

Following the insertion of the stent in the rabbit esophagus, both PEMS and SEMS were demonstrated to cause tissue hyperemia, proximal obstruction, thickening of the epithelial layer and inflammatory cell infiltrating. In the 1st, 2nd and 4th week, hyperemia was similar both the SEMS and PEMS groups. However, in the 6th week, hyperemia was more marked in the PEMS group, as compared with the SEMS group. Hyperemia was marked in the 1st and 2nd week in the SEMS group but then decreased in subsequent weeks. Conversely, hyperemia was low in the 1st and 2nd week in the PEMS group but then increased in the following weeks. This may be due to the fact that paclitaxel had the effect of promoting inflammation thereby causing persistent tissue hyperemia. In the 1st week no proximal obstruction of the uncovered stent segments was observed in either group, although in the following weeks stricture was noted in both groups. However, there was no significant difference between the two groups. The proximal obstruction of the proximal uncovered stent is associated with mechanical stimulation between the stent and esophageal mucosa and tissue overgrowth. Following microscopic observation, it was apparent that the thickness of the epithelia was similar in the SEMS and PEMS groups in the 1st and 2 nd weeks, although by 4 weeks the epithelial thickness was significantly different. In the 4th and 6th week, the epithelial layer was markedly thicker in the SEMS group compared with the PEMS group. Mavi et al (29) reported that inflammation promotes the growth of esophageal epithelia and fiber hyperplasia. However, the results of the present study were not concordant with those of previous reports $(17,21)$. The mechanism underlying the association between inflammation and the epithelia merits further study. Inflammatory cell infiltration was markedly high in the SEMS group in the 1st and 2nd week, and decreased over the following weeks. Conversely, inflammatory cell infiltration was low in the PEMS group at the 1 st and 2nd week, and increased in the 4th and 6th week. The inflammatory cell infiltration was different at different time points in the PEMS group. We think the reason for the change of inflammatory cell infiltration was the same as that of hyperemia. Notably, persistent inflammatory cell infiltration in the PEMS group also revealed the sustained release of paclitaxel at 6 weeks. The PEMS may inhibit tumor growth through the sustained released of paclitaxel, which exhibits anti-tumor effects and activates inflammation.

The limitations of the present study included the fact that the experiments were carried out on normal rabbit esophagus, and results obtained from a rabbit model may not generalize to the effect of PEMS in human patients with esophageal carcinoma. In addition, the mechanism underlying the effects of sustained released of paclitaxel on normal esophageal and cancerous cells requires further study.

In conclusion, endoscopic stent insertion into rabbit esophagus is safe and easily carried out. PEMS exhibited a steady release pattern of paclitaxel and may provide an alternative tool in the management of human esophageal squamous carcinoma.

\section{Acknowledgements}

The present study was partially supported by grants from the National Natural Science Foundation of China (grant nos. 81172266, 81273464, 81202474 and 30973651), the Science and Technology Support Program of Jiangsu Province (grant no. BE2010719), the Natural Science Foundation of Jiangsu Province (grant no. BK2011859) and Jiangsu Innovation of Medical Team and Leading Talents Cultivation (grant no. LJ201127). The authors would also like to thank Professor Yiqiao Hu at State Key Laboratory of Pharmaceutical Biotechnology, Nanjing University for generously providing the key techniques of producing the paclitaxel-eluting covered metal stents.

\section{References}

1. Pennathur A, Gibson MK, Jobe BA and Luketich JD: Oesophageal carcinoma. Lancet 381: 400-412, 2013.

2. Xing D, Tan W and Lin D: Genetic polymorphisms and susceptibility to esophageal cancer among Chinese population (review). Oncol Rep 10: 1615-1623, 2003.

3. Layke JC and Lopez PP: Esophageal cancer: A review and update. Am Fam Physician 73:2187-2194,2006.

4. Griffin SM and Lamb P: Oesophageal cancer. Surgery 24: 97-100, 2006

5. Johnson E, Enden T, Noreng HJ, Holck-Steen A, Gjerlaug BE, Morken T, Johannessen HO and Drolsum A: Survival and complications after insertion of self-expandablemetal stents for malignant oesophageal stenosis. Scand J Gastroenterol 41: 252-256, 2006

6. Rozanes I, Poyanli A and Acunaș B: Palliative treatment of inoperable malignant esophageal strictures with metal stents: One center's experience with four different stents. Eur J Radiol 43: 196-203, 2002.

7. Guo Q, Guo S and Wang Z: A type of esophageal stent coating composed of one 5-fluorouracil-containing EVA layer and one drug-free protective layer: In vitro release, permeation and mechanical properties. J Control Release 118: 318-324, 2007.

8. Kipshidze N: Current status of drug eluting stents. Curr Pharm Des 16: 3977, 2010.

9. López de Cicco R, Watson JC, Bassi DE, Litwin S and Klein-Szanto AJ: Simultaneous expression of furin and vascular endothelial growth factor in human oral tongue squamous cell carcinoma progression. Clin Cancer Res 10: 4480-4488, 2004.

10. Jeon SR, Eun SH, Shim CS, Ryu CB, Kim JO, Cho JY, Lee JS, Lee MS and Jin SY: Effect of drug-eluting metal stents in benign esophageal stricture: An in vivo animal study. Endoscopy 41: 449-456, 2009.

11. Li J, Wang F, Sun D and Wang R: A review of the ligands and related targeting strategies for active targeting of paclitaxel to tumours. J Drug Target 15: 1-13, 2016. 
12. Rowinsky EK and Donehower RC: Paclitaxel (taxol). N Engl J Med 332: 1004-1014, 1995.

13. Huang J, Zhang Y, Zhong H, Fan Z, Jiang G, Shen Y, Song H, Tao $Z$ and Wang K: Comparison of endoscopic submuscosal implantation vs. surgical intramuscular implantation of VX2 fragments for establishing a rabbit esophageal tumor model formimicking human esophageal squamous carcinoma. PLoS One 9: e85326, 2014.

14. Lee DK, Kim HS, Kim KS, Lee WJ, Kim HK, Won YH, Byun YR, Kim MY, Baik SK and Kwon SO: The effect on porcine bile duct of a metallic stent covered with a Paclitaxel-incorporated membrane. Gastrointest Endosc 61: 296-301, 2005.

15. Stokes WS: Best practices for the use of animals in toxicological research and testing. Ann N Y Acad Sci 1245:17-20,2011.

16. Huang J, Shuang J, Xiong G, Wang X, Zhang Y, Tang X, Fan Z, Shen Y, Song $\mathrm{H}$ and Liu Z. Establishing a rabbit model of malignant esophagostenosis using the endoscopic implantation technique for studies on stent innovation. J Transl Med 12: 40, 2014.

17. Lee SS, Shin JH, Han JM, Cho CH, Kim MH, Lee SK, Kim JH, Kim KR, Shin KM, Won YH and Song HY: Histologic influence of Paclitaxel-eluting covered metallic stents in a canine biliary model. Gastrointest Endosc 69: 1140-1147, 2009.

18. Zhang HZ, Jin GF and Shen HB: Epidemiologic differences in esophageal cancer between Asian and Western populations. Chin J Canc 31: 281-286, 2012

19. Müller JM, Erasmi H, Stelzner M, Zieren U and Pichlmaier H: Surgical therapy of oesophageal carcinoma. Br J Surg 77 845-857, 1990.

20. Talukdar FR, Ghosh SK, Laskar RS and Mondal R: Epigenetic, genetic and environmental interactions in esophageal squamous cell carcinoma from northeast India. PLoS One 8: e60996, 2013.

21. Lee DK, Kim HS, Kim KS, Lee WJ, Kim HK, Won YH, Byun YR, Kim MY, Baik SK and Kwon SO: The effect on porcine bile duct of a metallic stent covered with a paclitaxel-incorporated membrane. Gastrointest Endosc 61: 296-301, 2005.
22. Suk KT, Kim JW, Kim HS, Baik SK, Oh SJ, Lee SJ, Kim HG, Lee DH, Won YH and Lee DK: Human application of a metallic stent covered with a Paclitaxel-incorporated membrane for malignant biliary obstruction: Multicenter pilot study. Gastrointest Endosc 66: 798-803, 2007.

23. Song TJ, Lee SS, Yun SC, Park do H, Seo DW, Lee SK and Kim MH: Paclitaxel-eluting covered metal stents versus covered metal stents for distal malignant biliary obstruction: A prospective comparative pilot study. Gastrointest Endosc 73: 727-733, 2011.

24. Guo SR, Wang ZM, Zhang YQ, Lei L, Shi JM, Chen KM and Yu Z: In vivo evaluation of 5-fluorouracil-containing self-expandable nitinol stent in rabbits: Efficiency in long-term local drug delivery. J Pharm Sci 99: 3009-3018, 2010.

25. Kim EY, Park YS, Shin JH, Cho YJ, Shin DH, Yoon HK and Song HY: The effectiveness of erythromycin in reducing stent-related tissue hyperplasia: An experimental study with a rat esophageal model. Acta Radiol 53: 868-873, 2012.

26. Kapisiz A, Karabulut R, Sonmez K, Turkyilmaz Z, Poyraz A, Gulbahar O, Onal B, Ozbayoglu A and Basaklar AC: Effect of stent placement, balloon or cutting balloon dilatation on stricture formation after caustic esophageal burn in rats. Eur J Pediatr Surg 21: 258-262, 2011.

27. Speer E, Dunst CM, Shada A, Reavis KM and Swanström LL: Covered stents in cervical anastomoses following esophagectomy. Surg Endosc Nov 11, 2015: (Epub ahead of print)

28. Fuccio L, Hassan C, Frazzoni L, Miglio R and Repici A: Clinical outcomes following stent placement in refractory benign esophageal stricture: A systematic review and meta-analysis. Endoscopy 48: 141-8,2016.

29. Mavi P, Niranjan R, Dutt P, Zaidi A, Shukla JS, Korfhagen T and Mishra A: Allergen-induced resistin-like molecule (Relm)- $\alpha$ promotes esophageal epithelial cell hyperplasia in eosinophilic esophagitis. Am J Physiol Gastrointest Liver Physiol 307: G499-G507, 2014 